\title{
The troubles of train meal
}

\author{
Bingqing Ding \\ International Business School \\ Yunnan University of Finance and Economics \\ Kunming, China \\ 1446202654@qq.com
}

Wei Zhou*

International Business School

\author{
Yunnan University of Finance and Economics \\ Kunming, China \\ zw453@163.com
}

\section{Lin Tan}

International Business School

Yunnan University of Finance and Economics

Kunming, China

2554638065@qq.com

\begin{abstract}
The train into public life increasingly, travel, work and go to school by train become a way of people's choice, but the price and quality of train meal have became an obsession. This article mainly from three aspects which are supply, the balance between demand and supply and the elasticity of supply to explain why the train meal so expensive.
\end{abstract}

Keywords—train meal; supply; demand and supply equilibrium; the elasticity of supply

\section{INTRODUCTION}

Train is the common vehicle and has most number of passengers. When train as a convenient transportation shuttle, which shorten the distance between us, each passengers are inseparable from car snack food. Some scholars pointed that food prices on the train tend to more than a third higher than elsewhere [1]. So it can find that a considerable part of passengers carried a lot of baggage and convenience foods by train, which has become a unique landscape of Chinese railway passenger transport. With the rapid development of China's railway transport industry, the railway catering quality and safety issues have become increasingly prominent, for train meals everyone has common feeling is low quality and high price. As it says train catering prices are "profiteering zone", for travelers who year-round wear plum in a country's railway.

Then this article will analyze from the perspective of demand and supply. Apart from the analyze of food in train by demand and supply theory, some scholars also use demand and supply theory to analyze other things, such as, water supply and demand equilibrium problems have become the attention in recent years, researchers from different angles to explore it [2-4]. Yang et al. put forward the principles of ecocity-oriented water resources supply and demand balance analysis [5]. You et al. utilized the principle of supply and demand to analyze the water resources of Qiantang River [6]. Zhao et al. used the principle of supply and demand balance and gray system to forecast Kaifeng's water resources [7]. Wei et al. analyzed the supply and demand balance of water resources under different Inflow rate [8]. Wang et al. summarized a wide variety of supply and demand interaction form [9]. These applications of balance and supply theory show that demand and supply theory in dealing with the problem of water resource demand and supply, which is also a reason why we choose this method to analyze train meal.

Further, apart from the analysis of water resources, the demand and supply theory in other parts has acquired a lot of achievements. For example, Chen et al. established equilibrium model based on the market price of dairy supply and demand [10]. Huang et al. analyzed the status of coal demand and supply of China and predicted the domestic coal demand [11]. Xuan used supply and demand theory to analyze, the result showed that it was difficult to make adjustment in price based on changes in demand [12]. Wang and Yi put forward related macroeconomic regulation and control countermeasures to construct Guangzhou law carbon land traffic from supply and demand [13]. Ma et al. carried out the analysis of water demand and supply based on assessment of current water availability and its utilization [14]. The main objectives of the above are to show the application of demand and supply theory in coal material, the relationship between price and demand and so on.

Apart from the above mentioned issues, Liu et al. found that different supply and demand will lead to different food security situation [15]. Yang and Yi found that supply fluctuation and demand fluctuation will change the price of coal [16]. Li analyzed the main causes leading to demand and supply contradiction and influence factors [17]. Base on that, we will continue to introduce train meal based on demand and supply theory. Long distance travel by train is one of the most commonly used means of transport, which provide different grades and prices of service to different consumer groups, such as the provision of soft, hard, hard seat like,.

Therefore, the train has always been the most longdistance passenger transport vehicles. By train has many advantages, such as reasonable fares, fast delivery speed, high degree of safety, transport capacity, etc., but it also has many significant disadvantages, such as train cars crowded, hot, take your mind off the journey is hard. During the day, sleeping in snatches to the night, it is difficult to fall asleep. Even if you are lucky enough to get a sleeper, you spend half the night staring at the small blue light in the ceiling sleep or else as

\footnotetext{
* Corresponding author
} 
checked fumble your ticket. Once arrived at your destination almost exhausted.

When in train, fast food price is also a problem encountered by travelers. Train as public transport, in addition to profit, it also has the nature of public service. Apart from train operator monopoly, we just analyze from fast food itself, then the fast-food prices in the train mainly affected by supply and demand. People can not without eating, so if supply the train meal in market price, the demand for fast food will be very large. While the limited capacity of the car and along the supply is limited which will result in fast food in short supply, so in order to maintain the supply and demand balance, the relevant departments of train had to raise the price of fast food and reduce the demand of train meal.

Based on the literature review above and practical trends in train meal, this study proposes demand and supply theory and applies it to analyze train meal in China. In order to do that, this paper is organized as follows: The introduction in Section 1. The basic theory of demand and supply are proposed and their properties are discussed in Section 2. In Section 3, analyze the train meal condition. The paper ends with conclusions in Section 4. In Section 5, it's acknowledgement.

\section{THE THEORETICAL BASIS}

Demand and supply are the two contents of supply and demand theory, social needs is in the established level of development of production and distribution system, within the limits of their income that people can pay and willing to pay for material goods and services.

\section{A. Demand}

\section{1) The definition of demand}

Consumer demand means a commodity is willing and able to buy a number of requirement in a particular period of possible price [18], which can be represented by a formula: Needs $=$ desire to buy + purchasing power of the human, desire is a need a concrete manifestation, for example if you are hungry you need is to fill your stomach, then your concrete manifestation is what you want to eat. Need is a natural property because the natural properties can not be created, same as the demand.

\section{2) The demand function and factors of influence demand}

Many passengers need goods or services in the train. To do this, we use a function equation, i.e: $=\mathrm{f}(\mathrm{P}, \mathrm{T}, \mathrm{I}, \mathrm{E}, \mathrm{A})$, we have the basic factors influencing the market demand for more detailed analysis:

a) The price of the goods $(P)$. The demand and price has a reverse relationship. If the price increases, the demand of the product will decrease; if the price decrease, the demand of the product will increase.

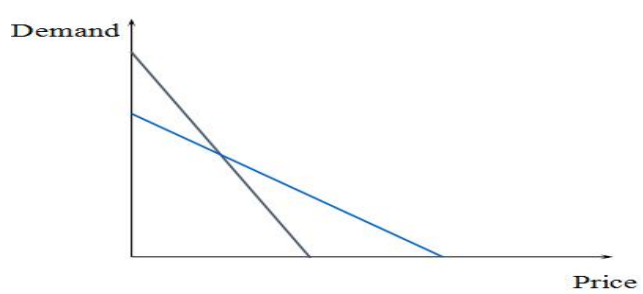

Fig. 1. Price demand curve.

b) Consumer preferences (T). Preference is the degree of consumer preferences for goods.

c) Consumer income (I). For most commodities, when the income levels of consumers rising, the demand for goods will also increase. Those goods are called normal goods. While other commodities, the increasing income levels of consumers, the demand for these goods will reduce low-grade products.

d) The price of alternatives. The alternative product is some products have similar values, they can replace each other to meet the needs of people.

e) The price of complementary products. The complementary goods means in order to meet the needs of some people one goods must combine with the use of other goods, such as cars and gasoline, household appliances and electricity. Between complementary goods, one of the commodity prices rising, the demand for the products will reduce and the demand for complementary products will decrease.

f) On the future price expectations (E). If consumers believe that the prices of some commodities are likely to rise, it will stimulate people to buy in advance; if the prices are likely to fall, many consumers will postpone the purchase.

g) Other factors (A). As the variety of goods, quality, advertising, location, season, climate, national policies, customs, etc., will also affect the demand for commodities.

\section{B. Supply}

Supply means that manufacturers are willing and able to provide a number of products in a variety of possible prices with in a certain period. As a result of supply should have two conditions: first is the desire to sell; second is having the capacity of supply. Both are indispensable. Whether on the train or elsewhere, it is impossible without food for people so there is a natural demand for trains snack in market conditions. It also has a direct relationship between the quantity of demand for fast food and the number of train passenger.

\section{Equilibrium Theory}

We will introduce two analysis theories about western economics of supply and demand which are equilibrium price theory and elasticity theory. The economic equilibrium in economic system references to a thing in the economic interaction among the various economic forces. If something about the economic aspects of force that can restrict each other or cancel each other out, then the economy will be in a 
relatively stable state and maintain the current situation unchanged. In the market, demand and supply can be considered as conflicting economic forces.

\section{Supply and demand elasticity}

\section{1) The definition of supply and demand elasticity}

Elasticity of supply and demand is reflected in the reaction or sensitivity of demand and supply of some variable changes. The variable factors of supply and demand are price, income and other related products' prices. Elasticity of demand includes price elasticity of demand, cross elasticity of demand, income elasticity of demand and the expected elasticity of demand and so on. We just analyze from the price elasticity of demand, that is to say, with respect to the extent change in quantity for a commodity, the relative reaction of the product prices in a period of time, which is the ratio between the percentage change in the demand and price.

\section{2) Categories of demand's price elasticity}

The kinds of price elasticity of demand can be divided into five situations: 1 . Price is not affected by the demand which is perfectly inelastic. 2 . When the price is fixed, the demand unlimited which is perfectly elastic demand. 3. Demand with price changes in the same proportion of single elastic. 4 . The percentage change in demand is greater than the percentage change in price elasticity. 5. To the contrary, lacking of flexibility. The main factors which influence the price elasticity of demand are alternative commodities extent, the use of extensive merchandise and the importance of commodity in consumers' life. The elasticity of supply is a measure of the amount of change in the supply of goods.

\section{3) Price elasticity of demand calculations.}

The methods to forecast the price elasticity of demand include: point elastic calculation method, the elastic interval calculation method and mathematical statistics. While we will choose two methods to introduce that are point elasticity and arc elasticity.

First, we will introduce point elasticity. It refers to a point of elasticity on the demand curve. Setting the price in period 1 and period 2 for the demand period 1 and period 2 respectively, then set the price increments is $\Delta P$ and incremental demand is $\Delta Q$, so its formula is: $=\frac{\Delta Q}{\Delta P}$. While the same kind of goods in different price ranges, its point of elasticity is also different.

The second is arc elasticity. The demand curve between two points is an arc elasticity. Using of arc elasticity calculation method to measure the price elasticity of demand mainly solve the point of embarrassment caused by lacking of information and data. It is the development of point elasticity computing methods.

\section{THE ACTUAL ANALYSIS}

Train is public transport which controlled by the government [19]. Allocation passenger evacuation is trains' nature of public service, but train service mainly demonstrate its' product attributes under normal circumstances. Offering meals is profitable in train, so all long-distance trains are running fast-food offer.

According to the definition of need and our nature understanding, there is a reverse relationship between price and demand. When other things being equal, demand will reduce with rising prices and increase with declining price [20]. But there is limiting for ruler of demand, it refers to general commodities. The train offers meals just trains' battalion business and the limited capacity of train cars, so train operators are unlikely to put all energy to supply fast food and train fast food supply amount is substantially stable. But the number of train passengers is large, their demand for fast food greatly exceeded the supply of train fast food.

In accordance with the principle of demand, if the price increases, the demand will reduce; to the contrary, if the price increase, the supply of products will increase. It is this interaction so the market is in equilibrium. Analyzing train fast food pricing issues, we can take static equilibrium analysis. According to the above definition of equilibrium, a commodity or service which has lower prices will encourage the demand as much as possible in the market. If the price is too high, the willing and ability of consumers to buy the products will be down. Otherwise, the supplier will increase prices as much as possible, if the price is too low, the number of willing and able to provide goods or services for sale will reduce. Therefore, when the power of supply and demand is in balance, the market prices tend to remain constant then the market is in equilibrium. If the price is above the equilibrium, this time the quantity of consumers willing and able to purchase goods will reduced, which means that the markets have over supply, some producers will not sell products. If the price higher than equilibrium which may lead commodity producers can not fulfill their production plans. In this case, some commodity producers will cut prices to sell, leading to price decline on the overall market. However, as long as the market price still over supply, the market price will be gradually reduced until it is equal to equilibrium price where the supply and demand is equal. Similarly, if the market price less than equilibrium price, everyone will rush to buy the products and the commodity producers will increase. For the above reasons, the market price will rise until it reaches equilibrium price. In general speaking, a commodity is always under the force of demand and supply in the market.

The number of fast food demand in the train is great, if the train snacks maintain the original price, then there will be competitive and not conducive to obtain excess profits. In this situation, in order to obtain extra profits and run the train safely and stably, the train operator will increase the price of products. In general, fast-food is daily consumer goods which lacks of elasticity of demand, but on the train, it will become a flexible rarities, therefore the price changes will greatly affect passengers' demand for fast food. As prices increase slowly, low-income passengers will start to reduce the demand of fast food. The higher the price of train snack; the less the demand of train meal until it reaches the equilibrium of supply and demand, thus the price of fast food on the train is much higher than in market. Meanwhile the choice of fast food in train is generally those with higher income or middle-income groups. 


\section{CONCLUSIONS}

We just analyzes fast food high prices in a train from the supply and demand, in fact, it also affected by other factors, such as the train is a monopoly sector, providing a large number of fast food will consume too much manpower and transportation costs, then at the same profits they will choose to maintain quantitative supply, raise prices to keep supply and demand balance.

High-price fast food in train has become the meal of majority high-income groups. A large number of migrant workers and students choose to ride the train but their will not buy fast food in train. I have several suggestions, such as the relevant departments take moderately lower prices and increase the supply of fast food, so that ordinary people are starting consumption. The second is more portable to consumers who buy some convenience foods, such as instant noodles, bread, milk, rice pudding and like,

\section{ACKNOWLEDGMENT}

This work was supported by the Science Foundation and Major Project of Educational Committee of Yunnan Province (No. 2014Z100); Applied Basic Research Programs of Yunnan Province (No. 2013FD029, and Philosophy and Social Science Foundation of Yunnan Province (Grant No. YB2015087)

\section{REFERENCES}

[1] J.H. He, Z.W. Ji, W.S. Wei, Q. Yang, M.L. Shan and Z.F. Zhou, "The problems and countermeasures of train snack," vol. 10, Cooking Knowledge, 2008, pp. 25-25.

[2] X.M. Cai, and M.W. Rosegrant, "Global water demand and supply projections: party a modeling approach," part 1: a modeling approach. vol. 27, Water International, 2002, pp. 159-169.

[3] Y.Q. Chen, "The supply and demand forecasting of cities with a shortage of water in yellow river basin area," The yellow river water conservancy press, Zhengzhou, 1997.

[4] M.A. Rayan, B. Djebedjian, and I. Khaled, "Water supply and demand and a desalination option for Sinai," Egypt, vol. 36, Desalination, 2001, pp.73-81.
[5] Z.F. Yang, Y.W. Zhao, B.S. Zhao, and Y.L. Hu, "Ecocity-oriented water resources supply-demand balance analysis," China Environmental Science, vol. 24, 2004, pp. 636-640.

[6] A.J. You, Z.C. Zeng, Y.B. Zhang, and L. Guo, "The analysis of Qiantang River water supply and demand and effective countermeasures," Journal of Hydraulic Engineering (S1), pp. 393-398, October 2007.

[7] J.L. Zhao, B.D. Zhao, J.F. Li, Z.G. Han, and X.M. Rong, "Water supply and demand balance and forecast analysis in urban- a case of Kaifeng city," Hydrological, vol. 29, pp. 50-57, December 2009.

[8] B.Wei, and X.Y. Lie, "Water supply and demand balance analysis based on the sustainable use in the county," vol. 36, Technical Supervision in Water, 2016, pp. 49-51.

[9] X.F. Wang, Y.P. Yun, and X.L. Wang, "Study and analysis on supplydemand interaction of power system under new circumstances," Chinese Society for Electrical Engineering, vol. 34, pp. 5018-5028, October 2014

[10] K.Y. Chen, C.Li, Y.Chen, and M.L. Xie, "Interaction of melamine incident and dairy supply and demand-based on the principles of economics," Business Research, 2011, pp. 8-10.

[11] Z. Huang, and R.F. Li, "Analysis and prediction of coal demand and supply in China during the 12th five year plan," vol. 36, China Coal, 2010, pp. 27-29.

[12] X. Xuan, "Using supply and demand theory of Keynesian to analyze the price of agricultural water," National Business·Theory, 2014, pp. 60-62.

[13] Y.M. Wang, and L.L. Yi, "Based on the theory of supply and demand construct Guangzhou law carbon land traffic control study," Ecological Economy, 2012, pp. 124-129.

[14] L.Y. Ma, L. Zhang, and Z.Y. Wu, "Analysis of water demand and supply in Yangtze river basin," China Water Resources, 2013, pp. 9-11.

[15] X.F. Liu, G.H. Chen, and Z.H. Sheng, "Food safety and government regulation strategies under the different relationship between supply and demand," China Management Science, vol. 18, pp. 143-150, 2010.

[16] D.Yang, and L.Q. Li, "Supply and demand fluctuation and price risk management of coal market," Coal Economic Research, 2014, pp. 10-12

[17] Z. Li, "A forecast and analysis of china's oil demand and supply trend and contradiction," Journal of Harbin University of Commerce: Social science, 2006, pp. 73-75.

[18] H.Y. Mainz, "The basic principle of supply and demand concepts Reconstruction Law," People's Forum, 2014, pp. 111-113.

[19] O. Sun, "Financial logistics demand and supply chain development based on analysis of Logistics," vol. 34, Technology: Equipment version, 2015, pp. 46-48.

[20] H.Y. Gao, "Western economics (microscopic section)," China Renmin University Press, 2011. 